Semantics \& Pragmatics Volume 6, Article 6: 1-29, 2013

O http://dx.doi.org/10.3765/sp.6.6

\title{
It's that, and that's it! \\ Exhaustivity and homogeneity presuppositions in clefts (and definites)*
}

\author{
Daniel Büring \\ University of Vienna
}

\author{
Manuel Križ \\ University of Vienna
}

Submitted 2011-07-21 / Accepted with revisions required 2011-09-12 / Revision received 2012-04-10 / Revisions requested 2012-07-20 / Revision received 2013-03-08 / Revisions requested 2013-03-29 / Final version received 2013-04-01 / Published 2013-08-13

\begin{abstract}
This paper proposes a way to encode exhaustivity in clefts as a presupposition, something which has been claimed to be adequate, but never successfully implemented. We furthermore show that the facts that prompted the need for such an analysis carry over to identity sentences with definite DPs and propose a way to achieve the same presuppositions for definite DPs.
\end{abstract}

Keywords: clefts, definites, presuppositions, homogeneity, exhaustivity

\section{Background: Exhaustivity in clefts}

A cleft of the form It is $x$ that $P$ not only expresses that $x$ has property $P$, but also that $x$ is the only individual to have $P$, i. e. that $x$ exhaustively identifies $P$ (in the relevant contextual domain). Call that the ExHAUSTIVITY CLAIM.

* Preliminary versions of this work were presented in 2010-12 at ZAS, Berlin, at the Thomasberg workshop in Austria, the UCSD linguistics colloquium, and at Sinn \& Bedeutung 17 in Paris; we thank the audiences there, and especially Ivano Caponigro, Regine Eckardt, Daniel Hole, Martin Prinzhorn, Floris Roelofson, Ede Zimmermann, Malte Zimmermann and two anonymous S\&P reviewers for their helpful comments on earlier versions. Part of this work was carried out while the first author was a visiting scholar at ZAS Berlin.

(C)2013 Daniel Büring and Manuel Križ

This is an open-access article distributed under the terms of a Creative Commons NonCommercial License (creativecommons.org/licenses/by-nc/3.o). 


\subsection{Exhaustivity is not part of the asserted/at-issue content}

As first argued in Halvorsen 1978: §1.4.2 and discussed in more detail in Horn 1981, the Exhaustivity Claim associated with clefts does not behave like a part of the at issue content, i. e. it does not appear to be asserted. This is particularly evident when we compare clefts to parallel sentences with only:

a. It was Fred she invited.

b. She only invited Fred.

Both sentences in (1) convey that she didn't invite anyone other than Fred. But only in (1b) does this seem to be part of the assertion. This becomes clear when we try to negate either of (1) for the sole reason that the Exhaustivity Claim is false (examples modelled on Horn 1981, exx. (11-12)):

(2) a. \#Bob knew she invited Fred, but he didn't know it was Fred she invited.

b. Bob knew she invited Fred, but he didn't know she only invited Fred.

(3) a. \#It wasn't Fred she invited. She also invited Gord.

b. \#It wasn't Fred she invited. She invited Fred and Gord. ${ }^{1}$

c. She didn't only invite Fred. She also invited Gord.

d. She didn't only invite Fred. She invited Fred and Gord.

(4) shows the perhaps simplest version of the contrast:

(4) a. \#She invited Fred, but it wasn't Fred she invited.

b. She invited Fred, but she didn't invite only Fred.

The contrasts in (2)-(4) makes sense if the Exhaustivity Claim is part of the assertion in only-sentences, but isn't in clefts.

Before going on, let us note that the negated clefts are usually taken to imply an existential statement, e. g. that she invited someone in (3a) and (3b), which is commonly analyzed as an existential presupposition of clefts in general. But note, too, that such an existential implication, whatever its nature, does not explain any of the contrasts above. We will assume for

1 One could claim that in certain contexts, (3b) is acceptable. Crucially, however, in such contexts, She didn't invite Fred, she invited Fred and Gord seems as good as (3b). In other words, (3b) has the general quality of a sentence in which negation targets a non-asserted aspect of the sentence's meaning. 
Exhaustivity and homogeneity presuppositions in clefts

the sake of concreteness that clefts do have an existential presupposition in addition to the Exhaustivity Claim, but nothing we say about exhaustivity hinges on that. Some further comments on the existential implication will be made in section 6 .

\subsection{Exhaustivity presuppositions?}

Given the data above, it is occasionally claimed that the Exhaustivity Claim is presupposed rather than asserted in clefts. ${ }^{2}$ But what is meant by this? Clearly, (5a/b) do not presuppose (5c) (see also Halvorsen 1978: 15, Atlas \& Levinson 1981: 24f.):

(5) a. It wasn't Fred she invited.

b. Was it Fred she invited?

c. She invited Fred and no-one else.

A similar objection can be raised against the idea that exhaustivity is conventionally implicated, since conventional implicatures are standardly held to survive under negation, question formation, etc. ${ }^{3}$

One could argue that the presupposition is instead that she invited exactly one individual, and more generally, that it was $x$ that $P$ presupposes that $P$ denotes a singleton set. This would successfully explain the ill-formedness of (2a), (3a) and (3b): Since Bob is presupposed to know that she invited exactly one person, he must therefore know that she invited only Fred if he knows that she invited Fred; similarly, a speaker who presupposes that she invited only one person (though not necessarily Fred) can't then assert that she invited Fred and Gord.

This explanation, however, wrongly predicts that (6) should be as bad as (3a) and (3b), since in (6) the second sentence, too, would contradict the singularity presupposition of the first:

(6) It wasn't Fred she invited. She invited Bob and Gord.

2 E. g. Wedgewood 2007: 215, echoed approvingly in Hedberg in press: 4. The problems for this view summarized in this section are for the most part already pointed out by Halvorsen (1978: 15ff.) and and Atlas \& Levinson (1981: 24f.). While Halvorsen 1978 explicitly leaves problems for further research, Atlas \& Levinson 1981 attempt a solution, which, however, fails to generalize, see the appendix.

3 This argument is already put forward by Horn (1981) against Halvorsen. Horn's own account of the Exhaustivity Claim as a conversational implicature falls short of providing a convincing derivation of the implicature and fails to explain its non-cancellability. 
Moreover, the phenomena can be replicated with plural clefts: ${ }^{4}$

(7) It wasn't Fred and Sue she invited. \#She invited Fred, Sue and Gord.

(8) \#John knew she invited Fred and Sue, but he didn't know it was Fred and Sue she invited.

Evidently, the first sentence in (7) and the second clause in (8) can't be said to presuppose that (John knows that) she invited exactly two people. Yet the sentences clearly imply that she invited Fred, Sue, and no-one else. So exhaustivity can't be derived from a singularity presupposition.

On the other hand, any parallel 'plural exhaustivity' would amount to nothing more than existence: there will be a maximal group of individuals that she invited whenever she invited someone. Clearly, presuppositions of this kind aren't going to give us exhaustivity in the plural case, and hence seem unpromising to help us in general.

Our problem, then, is that exhaustivity is somehow implied in clefts, but it seems to be neither asserted, nor presupposed or implicated.

\section{Towards a solution}

The idea we want to explore is that exhaustivity in clefts is indeed presuppositional, but that it is formulated in slightly different terms than one would expect. The presupposition of a cleft of the form it is $x$ that $P$ is that $x$ is not a proper part of the maximal member of $P$. For distributive predicates like invite, this boils down to the requirement that if $x$ is in $P$, it is the maximal $P$, i.e. the sum of all elements in $P$.

In the concrete case of (9), then, there is a presupposition that Fred is not a proper part of the sum of all invitees. As a result, he is either the sole invitee (=the 'sum' of all invitees), or he was not invited at all.

(9) It was Fred she invited.

a. Ass: She invited Fred.

b. PRES: Fred is not a proper part of the sum of all people invited by her.

We will consider the question how such a presupposition should come about in a moment. Let us first see how it addresses the problems noted in the

4 Atlas \& Levinson 1981: 25, 29f., Halvorsen 1978: 15f. 
Exhaustivity and homogeneity presuppositions in clefts

previous section. First, assertion and presupposition of (9) taken together correctly imply exhaustivity: She invited Fred and no-one else. Second, negation:

(10) It wasn't Fred she invited.

Ass: $\quad$ She did not invited Fred.

PRES: Fred is not a proper part of the sum of all invitees.

From the assertion and presupposition in (10), it does not follow that she invited Fred. Indeed, it doesn't even follow that she invited any single person (so we get (6) right); there may well have been a multitude of invitees, only they couldn't have included Fred. It does, however, follow that she didn't invite Fred (that is just the assertion). If it weren't for the presupposition, then a continuation of the form She invited Fred and ... would simply lead to a contradiction, but in fact we predict that such a scenario would result in a presupposition failure for the cleft, since if she invited Fred and someone else, then Fred is a proper part of the sum of all invitees. ${ }^{5}$

Third, consider belief contexts:

(11) \#Bob knew she invited Fred, but he didn't know it was Fred she invited.

By standard assumptions about presupposition projection under verba sentiendi (e. g. Heim 1983), Bob didn't know it was Fred she invited, assuming (16), presupposes that Bob knew that Fred isn't a proper part of the sum of all invitees, i. e. that either only Fred was invited, or Fred was not invited at all, and entails that Bob didn't know that she invited Fred. The latter, evidently, is incompatible with the first sentence in (11), which asserts that Bob knew she invited Fred. ${ }^{6}$

So the presupposition as made explicit in (9) looks promising for deriving the correct patterns. We now should turn to the question of how such a strange-sounding presupposition comes about, and what its proper formalization is. First, however, we would like to take the reader on a quick excursus.

5 As it happens, the presupposition in (10) is entailed by the assertion. This situation occurs in negated clefts at least with distributive predicates, but it has no obvious significance.

6 Indeed, the assertion of the first sentence together with the presupposition of the second entails that Bob knew she invited Fred and only Fred. This correctly predicts the oddness of (i), too, because new information can't be entirely presupposed:

(i) \#Bob knew she invited Fred. Indeed, he even knew that it was Fred she invited. 
Daniel Büring and Manuel Križ

\section{The connection with definites}

It has been proposed that a cleft like it was Fred she invited is the same - at some level of linguistic representation - as the parallel sentence with a definite description, the person(s) she invited was Fred. ${ }^{7}$ (Note that this rendering already takes into consideration that clefts are number-neutral.) Would adopting such a proposal give us the correct behavior for the Exhaustivity Claim (given that definite descriptions on many analyses are presuppositional)? It won't by itself. Without going into too much detail, consider two common interpretations for definite descriptions.

On a term (or Fregean) interpretation, 'the individual(s) she invited' denotes a (plural) individual if such an individual exists, and fails to denote otherwise. It correctly follows that 'the individual(s) she invited = Fred' implies (indeed asserts) exhaustivity. However, its negation, too, is defined as long as there is a (possibly plural) individual she invited, and true if that individual is not identical to Fred. This is clearly the case if, for example, she invited Fred and Gord (since Fred $\neq$ Fred $\sqcup$ Gord - where $\sqcup$ is the mereological sum (or fusion) operator of Link 1983). ${ }^{8}$ It is thus unclear what should be wrong with (3a), (3b), or (4); similar for the belief case.

On a presuppositional generalized quantifier (or Russellian) interpretation of definites, 'the individual(s) she invited' maps a property $Q$ to true if there is an individual $X$ she invited which has $Q$ and presupposes that every individual she invited is a part of $X$. 'The individual(s) she invited $\neq$ Fred' (i. e. $Q$ is the property of not being Fred) is thus again true if the maximal individual she invited is not Fred, including the case in which it is the sum of Fred and Gord. So in either case, even if we grant a presuppositional analysis, we don't get exhaustivity to be part of that presupposition.

What was a problem for the analysis of clefts thus turns out to be a problem for the analysis of identity statements with definite descriptions as well, for those pattern just like clefts with respect to the exhaustivity facts (we

7 Akmajian 1970, Han\&Hedberg 2008, Harries-Delisle 1978, Hedberg 2000, Percus 1997. The proposal by Atlas \& Levinson (1981: 53ff.) is billed as an implementation of this intuition, too; it is dicussed in the appendix.

8 As usual:

(i) $\quad$ a. $X \subseteq Y$, ' $X$ is a mereological part of $Y^{\prime}$, iff $X \sqcup Y=Y$

b. $X \sqsubset Y$, ' $X$ is a proper mereological part of $Y$ ', iff $X \subseteq Y$ and not $Y \subseteq X$

c. $X \not \subset Y$ if not $X \sqsubset Y$ 
Exhaustivity and homogeneity presuppositions in clefts

use plural examples to avoid the awkward person(s)... is/are circumscription):

(12) \#The people she invited weren't Fred and Sue. She invited Fred, Sue and Gord.

(13) \#John knew she invited Fred and Sue, but he didn't know the people she invited were Fred and Sue

That is to say, the parallelism between clefts and identity statement with definites extends to the status of exhaustivity as non-asserted. The problem lies not with the idea that clefts underlyingly involve definites, but with an inadequate semantics for definites. Rather than presupposing that there is a maximal group of individuals she invited, which is what standard analyses of the people she invited predict (and which comes down to a mere existential presupposition, as discussed above), it should hold here, too, that:

(14) The people she invited were Fred and Sue.

Ass: She invited Fred and Sue.

PRES: Fred and Sue are not proper parts of the sum of all invitees.

Let us summarize at this point: We have run into two problems related to exhaustivity, one in clefts, one in identity statements with definite descriptions. In both cases, exhaustivity apparently needs to be coded in a somewhat non-obvious manner with reference to mereological parthood. We believe that this is underlyingly the same phenomenon and thus concur with e.g. Percus (1997), according to whom clefts are statements of the form 'the one(s) who... are...' at Logical Form. In the following, we will discuss further steps towards an analysis in terms of identity statements.

\section{How to encode the exhaustiveness presupposition}

\subsection{Exhaustivity as uniformity in definites}

Our formulation of the exhaustivity presupposition may have sounded strange, making reference to mereological parthood. But there is another phenomenon surrounding definites, often considered a presupposition (albeit an easily accommodated one), which has to do with such notions. The sentence The boys went swimming is true if all the boys went swimming, but it is false only if none of them went swimming. It thus seems to have a presupposition that either all or none of the boys went swimming. 
The phenomenon is often called homogeneity, but proposals about it are found in Fodor 1970, Löbner 1987: 83 and 2000: 239ff., as well as - extending to other phenomena than definite descriptions - von Fintel 1997, Schwarzschild 1994: 220, and Gajewski 2005, under various names. We call this the Uniformity presupposition of definites, and give it again a slightly unusual formulation: a sentence of the form [the $P] Q$ presupposes that either the entire group of $P \mathrm{~s}$ is $Q$ or nothing in $Q$ is a proper part of the maximal $P .{ }^{9}$

To be able to state this formally most conveniently, we assume with e. g. Schwarzschild (1994) and Champollion (2010) that natural language predicates are always closed under mereological fusion..$^{10}$ This means that every non-empty predicate has a maximal element. We therefore don't need the star operators that are commonly used to indicate closure under sum formation. Now we can state the presupposition of definites generally and formally:

(15) The $P$ are $Q$.

Ass: $\quad \sqcup \llbracket P \rrbracket \in \llbracket Q \rrbracket$

PRES: $\quad \sqcup \llbracket P \rrbracket \in \llbracket Q \rrbracket \vee \neg \exists x \in \llbracket Q \rrbracket[x \sqsubset \sqcup \llbracket P \rrbracket]$

Applied to a standard example, this translates to the following: ${ }^{11}$

(16) The boys went swimming.

Ass: All the boys went swimming.

PRES: All the boys went swimming or no proper part of the boys went swimming (no swimmer is a proper part of the sum of boys).

This analysis predicts nothing new for the positive case. It does predict that The boys didn't go swimming implies that none of the boys went swimming, which strikes us as desirable (see also the discussion in the sources quoted above). It also predicts the contrast in (17):

a. A: The boys went swimming.

B: \#No, the boys didn't go swimming. Mike stayed at the shore.

9 In case $Q$ is a distributive predicate, that - even more simply - means that every or no $P$ $Q$ s. Thanks to an anonymous reviewer for making us point this out clearly.

10 That is to say, $P(x) \wedge P(y) \rightarrow P(x \sqcup y)$.

11 We are aware that due to the nature of the $\sqcup$ operator, this formulation implies an existence presupposition. It is straightforward to give an alternative formalization that doesn't have this effect, based on the (possibly empty) set of maximal Ps, which, however, would only hinder the exposition at this point. 
Exhaustivity and homogeneity presuppositions in clefts

b. A: The boys went swimming.

B: Well, not all the boys went swimming. Mike stayed at the shore.

There are probably other ways to explain this contrast, but at least the general effect of the presupposition in (15) doesn't strike us as problematic in the light of such examples.

\subsection{Clefts with definites}

Applying (15) to clefts, the role of $P$, the restrictor of the definite, is now played by the relative clause, while the role of $Q$ is taken by the predicate of being identical to the pivot (the constituent that is clefted, in this case $a$ ):

(18) It was $a$ that $P$.

Ass: $\quad \sqcup \llbracket P \rrbracket \in(\lambda x \cdot x=\llbracket a \rrbracket)$

PRES: $\quad \sqcup \llbracket P \rrbracket \in(\lambda x \cdot x=\llbracket a \rrbracket) \vee \neg \exists y \in[\lambda x \cdot x=\llbracket a \rrbracket][x \sqsubset \sqcup \llbracket P \rrbracket]$

This conveniently reduces to the following:

(19) $\quad$ Ass: $\quad \sqcup \llbracket P \rrbracket=\llbracket a \rrbracket$

PRES: $\llbracket a \rrbracket \not \subset \sqcup \llbracket P \rrbracket$

The presupposition is precisely the one we formulated in section 2: $a$ is not a proper part of the maximal $P$.

For reasons that will become clear in sections 5 and 6 below, it is preferable to not speak about the maximal $P$, but about the set of maximal $P$ s instead. Given our assumption that predicates are closed under mereological fusion, this set will always be a singleton for predicates of individuals. We then end up with the following variant of (19) as our final formulation. (An analogous adjustment could and perhaps should be made for definites.)

(20) Ass: $\llbracket P \rrbracket(\llbracket a \rrbracket)$

PRES: $\forall x \in \max (\llbracket P \rrbracket): \llbracket a \rrbracket \not \subset x$

(where for any $P \in D_{e t}, \max (P)=\{x \in P \mid \neg \exists y \in P[x \sqsubset y]\}$

Finally, for ease of use, we roll $(20 a+b)$ into a single operator CLEFT (where the formula between the colon and the period in (21) defines the domain of the partial function, which can be thought of as its presupposition, see e.g. Heim \& Kratzer 1998, ch.4.4.):

$$
\text { CLEFT }:=\lambda z \cdot \lambda P: \forall x \in \max (P)[z \not \subset x] . P(z)
$$


Daniel Büring and Manuel Križ

\subsection{Parthood and collectivity}

Looking at (20)/(21), note that we stated the presupposition as ' $a$ is not a proper part of a maximal $P$ (which, in the case of predicates of individuals, reduces to '.. of the sum of all $P$ s'), rather than the seemingly simpler ' $a$ is not in $P$ or it is a maximal $P$ '. ${ }^{12}$ These two options are indeed equivalent as long as we consider distributive predicates only, since it will hold for any distributive predicate $P$ that $a$ is a proper part of $\sqcup P$ iff $a \in P$. But once we take non-distributive predicates into account, our proposal actually makes different predictions from the one stated in terms of $a \in P$. Consider a predicate like carry the piano, which can hold of either atoms or sums, and is not distributive.

Assume Bill and Fred carried the piano together, and neither of them did alone, nor did anyone else. We believe that (22) should suffer a presupposition failure in this case.

(22) It was Bill who carried the piano.

On our account in (20), this is predicted. Given that Bill isn't a (the) maximal piano-carrier - he didn't carry a piano alone and exclusively - , the presupposition of the cleft requires that he not be a mereological part of the maximal piano-carrier, i. e. that he wasn't involved in any piano-carrying at all. But he did in our scenario, because he carried a piano together with Fred, so the presupposition fails.

If, on the other hand, we used the presupposition that if Bill carried the piano, he is the maximal piano carrier, we would predict (22) to simply be false, since the singular individual Bill is not in the extension of carried the piano (which contains just the plural individual of Bill and John), so that the conditional presupposition would be true because its antecedent is false. ${ }^{13}$

In sum, we believe that distributive and collective predicates behave

12 This was in fact the proposal in Büring 2011, where the presupposition was stated conditionally as 'if $P(a)$, then $a=\sqcup P$ ' (in present notation), which is transparently equivalent to $(a=\sqcup P) \vee \neg P(a)$, the presupposition contemplated in the main text.

13 Conversely, if Bill alone somehow managed to carry the piano, and Fred had no part in it (and didn't carry a piano by himself either), then we predict (i) to be, not undefined, but false:

(i) If was Bill and Fred who carried the piano.

This is because Bill $\sqcup$ Fred is not in the extension of carried the piano, and is also not part of anything in that set, i.e. is not a part of Bill. The result strikes us as the correct one. 
identically in clefts: If $a$ is a proper part of those who $Q$, it was a that Qed is undefined, rather than false. Stating the presupposition of clefts in terms of part-hood to a maximal $Q$, as we did in (20), rather than in terms of having $Q$, correctly derives this parallelism.

The analogy we draw between clefts and definites predicts that the latter also show corresponding effects with collective predicates. In particular, the two sentences in (23) should have the same presupposition.

(23) a. It was Bill and Fred that carried the piano.

b. The people who carried the piano were Bill and Fred.

This, we believe, is the case. In a scenario where the piano was in fact carried by Bill, Fred and Mary together, both sentences are undefined, rather than false. Conversely, if Bill and Fred carried the piano, then (24b) is just like (24a): false.

(24) a. It was Bill, Fred and Mary that carried the piano.

b. The people who carried the piano were Bill, Fred and Mary.

\subsection{Presupposition, conventional implicature, or what?}

So far, we have described exhaustivity, via uniformity, as a presupposition, which is also the stance taken in much of the literature on the latter phenomenon. In fact, however, they are not particularly prototypical presuppositions. If we tell you that the boys went swimming, you need not really have assumed previously that all of the boys did the same thing. This is also evident in clefts. In order to be informed by us that it was Fred who was invited, it is does not seem necessary for you to have any prior beliefs about Fred; in particular, you need not have had any commitment to the position that while Fred may or may not have been invited, if he was, then he was the only one.

So while clearly not at-issue content, the Exhaustivity Claim still seems to be something that is communicated, as opposed to presupposed. So should exhaustivity in clefts and definites rather be modelled as a conventional implicature? Like presuppositions, conventional implicature are not part of the assertion, yet they can, and routinely are, used to convey new information; this seems to be the right mix of properties. However, it turns out that the Exhaustivity Claim differs from conventional implicatures in at least one crucial respect: it is strictly local. 
For example, (25) ascribes to Peter the belief that no-one other than Fred was invited. As a consequence, (26) sounds contradictory:

(25) Peter believes that it was Fred she invited.

(26) I think only one person was invited. Peter believes that it was Fred who was invited, \#and that Sue and Gord were, too.

In particular, the second sentence in (26) can't be interpreted to mean that Peter believes that Fred and Sue and Gord were invited, whereas the Exhaustivity Claim - that if Fred was invited, no one else was - would be ascribed to the speaker.

In contrast, as observed by Potts (2007: 477), a conventional implicature, e.g. triggered by an appositive, can be attributed to the speaker, even if embedded under a verb of saying or thinking:

(27) Sheila says that Chuck, a confirmed psychopath, is fit to watch the kids.

That is to say, the claim that Chuck is a confirmed psychopath (the conventional implicature) need not be part of what Sheila said (and hence she doesn't have to hold the strange attitude that a confirmed psychopath is fit to watch the kids) (these are the 'editorial comments' in Bach 1999: 339).

Presumably it is a hallmark of presuppositions, as opposed to conventional implicatures, that they need to be met in the local context in which the sentence triggering them is evaluated. Since this appears to be the case for the Exhaustivity Claim, witness (26), we choose to characterize it as a presupposition. The reason why it often seems to be communicated content, we suggest, is that this presupposition is just extremely easy to accomodate. This is similar to the way in which definite descriptions are often used to inform the hearer of the existence of the described object. In principle, however, any dimension of meaning that delivers locality in this sense would be appropriate.

This concludes the presentation of our main proposal and the motivation for it. In the following sections, we will extent our treatment to more complex examples and discuss its predictions (section 5), and add some more speculative remarks (section 6). 
Exhaustivity and homogeneity presuppositions in clefts

\section{Extensions}

Our semantics for clefts from section 4.2 requires that the pivot is an individual and that the meaning of the relative clause is a predicate of individuals. There also has to be a notion of parthood that is defined for individuals. But there are many clefts the pivots of which are not individuals. For instance, it is perfectly unremarkable to have a quantifier in that position.

(28) It was a hat that I bought.

For (28) and many cases like it, it would be semantically adequate to simply quantify into the cleft after raising the quantifier, as illustrated in (29).

(29) It was a hat that I bought.

a. [a hat] $\lambda y$.it was $y$ that I bought

b. $[\lambda P . \exists x[\operatorname{hat}(x) \wedge P(x)]](\lambda y \cdot \operatorname{CLEFT}(\lambda z$.bought $(\mathrm{I}, z))(y))$

c. $\equiv \exists x$ : hat $(x) \wedge \operatorname{CLEFT}(\lambda z$.bought $(\mathrm{I}, z))(x)$

This gives us the right result: there is a hat $x$ that was among my acquisitions, and that hat is not a proper part of the 'maximal acquisition', so it must be the maximal acquisition, i. e. the one thing that I bought. (29) ist predicted to be undefined if I also bought something else, and false if I only bought one or more non-hats.

In other cases, however, quantifying in will not yield the correct result. To focus on a particularly blatant failure, it was pointed out to us by an anonymous reviewer that DPs with just are perfectly acceptable and informative in clefts, and so are, we believe, those with only, which we will assume to be synonymous for our purposes:

(30) (A: I know Fred bought a copy of my book. Did anyone else?)

B: No, it was just/only Fred who bought it.

The problem is this: On the one hand, sentences with only are generally held to presuppose their so-called prejacent, i. e. the content of the parallel clause without only (or something implying that, see below): not only Fred bought a copy of my book implies that Fred bought a copy of my book (Horn 1969, Rooth 1985, a.m. o.).

On the other hand, according to the analysis developed here, a cleft of the form It was $X$ who $P$ presupposes that if $X$ is (part of) a $P$-er, $X$ is the maximal P-er: It was(n't) Fred who bought a copy of my book implies that if 
Fred bought a copy, no one else did.

Taken together, these two presuppositions seem to entail that Fred bought a copy (only) and that no one else did (cleft, together with first presupposition); and this is in fact just what we'll get formally if we scope out only Fred. But this seems implausible for (30), because it would leave nothing for it to assert. And it seems downright disastrous for (31), which clearly should not presuppose that Fred and no one but Fred bought a copy:

(31) It wasn't just/only Fred who bought it.

The problem does not lie, we think, with the alleged presupposition of only: (31) does imply that Fred bought it, and it seems plausible that indeed both (31) and (30) presuppose that. So even if we availed ourselves of one of the weaker lexical presuppositions occasionally proposed for only (e.g. Horn 1996, Ippolito 2008, McCawley 1981), as long as we concede that in our specific examples the sentence as a whole implies that Fred bought a copy of my book, the problem remains. ${ }^{14}$ It rather seems to be the Exhaustivity Claim connected with clefts that needs to disappear in these examples: if Fred and Marge wanted it, (32a) is clearly true, where (32b) is truth-value-less (as discussed at length above):

(32) a. It wasn't only Fred who wanted it.

b. It wasn't Fred who wanted it.

So (32a) (and arguably clefts with only in general) should not presuppose anything to the effect that if Fred wanted it, no one else did. It seems like the quantifier denoted by only Fred, not an individual variable bound by it, should be the argument to CLEFT here.

A second, more obvious limitation of quantifying in can be seen with intensional clefts; consider for example the prominent readings of the examples in (33): 15

(33) a. It was a multicultural environment that I was looking for.

b. It was a new hat that I wanted.

14 Similarly if we follow the suggestion in sec. 8 of Kiss 1998 according to which csak, 'only', in Hungarian focus constructions is the evaluative, rather than the exclusive only. For the English cases, this simply doesn't do justice to the intuitive content of sentences like (30) and (31).

15 Similar examples e. g. in Halvorsen 1978: §1.4.3. 
Exhaustivity and homogeneity presuppositions in clefts

Quantifying into the cleft here would only give us a de re reading. In order to get the prominent de dicto reading, the relative clause should abstract over quantifier intensions, along the lines of (34), and the intension of the quantifier denoted by a new hat, (35), should be the other argument of CLEFT: ${ }^{16}$

(34) $\lambda \mathcal{Q}_{s((e t) t)}$.I want in the evaluation world that $\lambda w \cdot \mathcal{Q}_{w}(\lambda x$.I have $x$ in $w)$

(35) $\lambda w \lambda P . \exists x[x$ is a new hat in $w$ and $P(x)]$

What we need to do is therefore to extend the proposal to pivots whose meanings are quantificational, which poses the challenge of defining a notion of parthood among quantifiers, as the CLEFT-operator relies on that notion.

\subsection{Extensional quantifiers}

It is easy to obtain the structure required for our cleft operator by type-lifting the cleft predicate $P$ to $\lambda \mathcal{P} . \mathcal{P}(P)$, i. e. the set of quantifiers that are true of the predicate. Assuming that we have a notion of parthood for quantifiers, we can then apply our meaning schema (20):

(36) It was $\mathcal{Q}_{(e t) t}$ that $P_{(e t)}$.

$$
\begin{aligned}
& \text { Ass: } \quad[\lambda \mathcal{P} . \mathcal{P}(P)](\mathcal{Q}) \quad(\equiv \mathcal{Q}(P)) \\
& \text { ' } \mathcal{Q} \text { is true of } P \text { ' } \\
& \text { PRES: } \forall \mathcal{Q} \text { ' } \max (\lambda \mathcal{P} . \mathcal{P}(P)): \mathcal{Q} \not \subset \mathcal{Q}^{\prime} \\
& \text { ' } \mathcal{Q} \text { is not a part of any maximal quantifier that is true of } P \text { ' }
\end{aligned}
$$

We now see the reason why in section 4.2 , we chose to speak about the pivot being among the maximal $P$ s, and not the maximal $P$, even though the latter would have been more natural for individual pivots: one and the same situation can be described with several quantificational clefts, e.g. (37b-d):

(37) Context: Peter saw his sisters Mary and Sue, and no one else.
a. It was Mary and Sue who Peter saw.
b. It was two of his sisters that Peter saw.
c. It was two girls that Peter saw.
d. It was no boy that Peter saw.

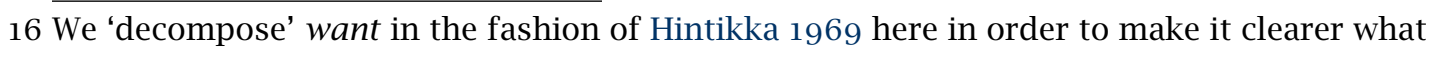
we need to quantify over. 
While (37a) names the maximal indidvidual - Mary $\sqcup$ Sue - that makes the predicate true in this scenario, any of the generalized quantifiers in $(37 \mathrm{~b}-\mathrm{d})$ correctly describes that scenario, too, and hence must be maximal (since they occur in a cleft), without one being part of the other - neither intuitively nor, as we will see momentarily, formally.

Intuitively, what we want is that a generalized quantifier $\mathcal{P}$ is a part of one $\mathcal{Q}$ if the latter implies that more individuals are involved. Fortunately, to get that, we can make use of a different notion of exhaustivity as discussed in the context of answers to questions (Groenendijk\&Stokhof 1984, Sevi 2005, van Rooij \& Schulz 2006 and others). Exhaustivity in this sense is a relation between a quantifier and a predicate, and what it says is, intuitively, that the predicate is true of a set of individuals that is sufficient to make the quantifier true of it, and of no other individuals. We will leave open the precise definition of exhaustivity and will just write $\operatorname{exh}(\mathcal{Q}, P)$, but we assume that a theory of exhaustivity in this sense delivers, among others, the following as theorems (that of Sevi 2005 does so; van Rooij \& Schulz 2006 yields all except $\left.(38 f)^{17}\right)$ :

(38) a. The quantifier-shifted individual $\lambda P . P(a)$ exhausts $\{a\}$ and nothing else.

b. $\llbracket$ only DP $\rrbracket$ exhausts the same predicates that $\llbracket \mathrm{DP} \rrbracket$ exhausts.

c. $\llbracket \mathrm{a}$ and $\mathrm{b} \rrbracket$ exhausts $\{a, b, a \sqcup b\} .^{18}$

d. $\llbracket n \mathrm{NP} \rrbracket$ exhausts any predicate that is true of exactly $n$ members of $\llbracket N P \rrbracket$.

e. $\llbracket a$ or $b \rrbracket$ exhausts $\{a\}$ and $\{b\}$ and nothing else.

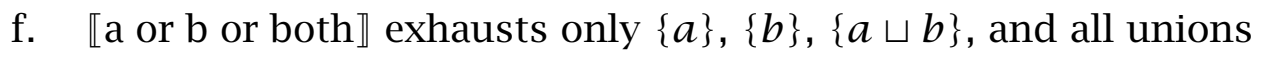
of those.

g. 【more than $n \mathrm{NP} \rrbracket$ exhausts any predicate true of $n+1$ or more members of $\llbracket N P \rrbracket$, and only those.

h. $\llbracket$ fewer than $n \mathrm{NP} \rrbracket$ exhausts any predicate true of $n-1$ or fewer members of $\llbracket \mathrm{NP} \rrbracket$, and only those.

Based on such a notion of exhaustivity, we can now define parthood among quantifiers as follows:

17 This is related to a shortcoming of their account in general, which predicts that the exhaustive interpretation of $A$ boy and a girl carried the piano is false if both of them are very strong and carried one piano each.

18 Where $a=\llbracket \mathrm{a} \rrbracket$, etc. 
Exhaustivity and homogeneity presuppositions in clefts

(39) A quantifier $\mathcal{P}$ is a proper part of a quantifier $\mathcal{Q}$ (written $\mathcal{P} \sqsubset \mathcal{Q}$ ) iff

1. $\exists P: \mathcal{P}(P) \wedge \operatorname{exh}(\mathcal{Q}, P)$, and

2. $\forall P: \mathcal{Q}(P) \rightarrow \neg \operatorname{exh}(\mathcal{P}, P)$.

Condition 1 says that the smaller quantifier is consistent with the exhaustivized version of the larger. ${ }^{19}$

Condition 2 requires that the larger quantifier entail that the smaller quantifier doesn't hold exhaustively. It straightforwardly implements the idea mentioned above that the larger quantifier somehow says that additional individuals are involved which are not required by the smaller quantifier.

Note that it follows that being exhaustively true of a predicate $P$ and being among the maximal quantifiers that are true of $P$ are equivalent, which is intuitively what we want. ${ }^{20}$

Let us now illustrate how this definition does what it is supposed to. We want (40) to have a presupposition failure if I bought anything in addition to the

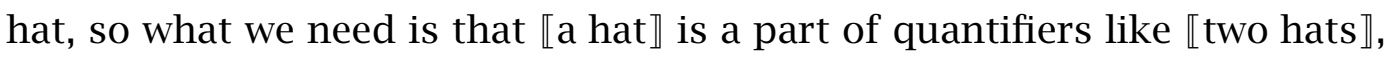
$\llbracket$ more than one hat $\rrbracket$, and $\llbracket a$ hat and a coat .

(40) It's a hat that I bought.

We can easily see that this is the case. Looking at the parthood relation between $\llbracket$ a hat $\rrbracket$ and $\llbracket$ two hats $\rrbracket$, the witnesses for Condition 1 are just sets that contain two hats. Since $\llbracket a$ hat $\rrbracket$ is exhaustively true only of singletons

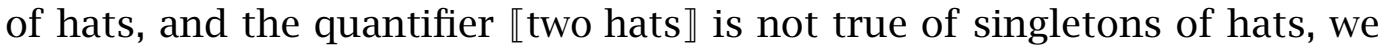
immediately see that Condition 2 is fulfilled as well. What we do not want

19 Again, we could not express this with the seemingly more straightforward $\forall P: \mathcal{Q}(P) \rightarrow \mathcal{P}(P)$, because of collective Ps. A boy should be part of a boy and a girl, but from $A$ boy and a girl carried the piano upstairs it does not necessarily follow that $A$ boy carried the piano upstairs, in case boy and girl only jointly carried the piano; Condition 1 is therefore weakened to say that this is the case for some predicates (namely all distributive ones).

20 Proof:

Left to right: Assume that $\mathcal{P}$ exhausts $P$, but that there is a quantifier $\mathcal{Q} \sqsupset \mathcal{P}$ that is also true of $P$. The contradiction with Condition 2 of parthood is immediately visible, $P$ being the counterexample to the universal quantification.

Right to left: Assume that $\mathcal{P}$ is a maximal quantifier that is true of $P$, but that it does not exhaust $P$. For every predicate $P$, there is the quantifier $Q=\lambda P^{\prime} . P^{\prime}=P$, which holds of $P$ and exhausts $P$. We can now show that $\mathcal{P}$ is a part of $\mathcal{Q}$ and thus is not a maximal quantifier that is true of $P$, contrary to the assumption. Condition 1 of quantifier parthood is obviously fulfilled, with $P$ being a witness. Since $\mathcal{Q}$ is true of only one predicate, namely $P$, of which $\mathcal{P}$ is not exhaustively true, Condition 2 holds as well. 
is for $\llbracket$ a hat $\rrbracket$ to be a part of $\llbracket$ less than three hats $\rrbracket$, for that would mean that 『a hat $\rrbracket$ can never be a cleft pivot: after all, its exhaustivized form, which is

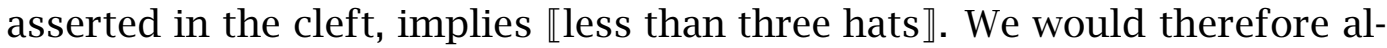
ways have to use less than three hats $\rrbracket$ in a cleft describing such a situation. Fortunately, Condition 2 is violated in this case, because there are predicates of which both quantifiers are true exhaustively: singletons of hats.

Then there are negative existentials like no boy. These can be proven to never participate in any parthood relations. They cannot ever be part of any other quantifier because for them, exhaustification is vacuous, but the conjunction of the two conditions requires that there is a predicate for which the smaller quantifier is true, but not exhaustively so (the witness for the existential quantifier in Condition 1). Hence the negative existential cannot be such a smaller quantifier. Neither can anything be a part of, say, «no boy In order for $\mathcal{P}$ to be a part of $\llbracket$ no boy $\rrbracket$, it would have to be the case that $\operatorname{exh}(\mathcal{P}, P)$ implies that there is a boy in $P$ (by contraposition of Condition 2). At the same time Condition 1 requires that $\mathcal{P}$ be true of at least one predicate that does not contain any boys. Call that one predicate $Q$. A proper definition of exhaustivity (the ones that we are aware of do so) will entail that if a quantifier is true of a predicate $P$, then there is a $P^{\prime} \subseteq P$ such that the quantifier is exhaustively true of $P^{\prime}$. This means that there is a subset of $Q$, which, of course, also contains no boys, of which $\mathcal{P}$ is exhaustively true. This contradicts the previous inference that any predicate that $\mathcal{P}$ is true of exhaustively must contain a boy. Hence, $\mathcal{P}$ cannot be a part of $\llbracket$ no boy $\rrbracket$.

The prediction that this makes for clefts is that clefts with negative existentials as pivots do not, in fact, have a presupposition; at least no presupposition beyond maybe an existence presupposition, which is not our concern. This strikes us as correct, as we cannot find anything related to exhaustivity in (41).

(41) It was no boy that came.

\subsection{Only explained}

We are now in a position to explain the behavior of only in clefts, which ostensibly makes the exhaustivity presupposition disappear. To that end, assume that only $D P$ is a quantifier with the meaning $\lambda P: \llbracket \mathrm{DP} \rrbracket(P) \cdot \operatorname{exh}(\llbracket \mathrm{DP} \rrbracket, P)$; that is to say, it presupposes that the quantifier $D P$ is true of the predicate, and asserts that it is exhaustively true. Since iteration of the exhaustivity operator 
Exhaustivity and homogeneity presuppositions in clefts

is vacuous, it follows that only $D P$ is exhaustively true of any predicate that it is true of. As we saw above in the case of negative existentials, this means that only DP cannot be a part of any other quantifier, since the definition of parthood requires, per Condition 1, that a quantifier that is part of another quantifier be true, but not exhaustively true, of at least one predicate (of which the other is exhaustively true). It must be noted, though, that it is possible for other quantifiers to be a part of only $D P$, namely exactly those that that are part of $D P$ anyway. ${ }^{21}$

Per our semantics for clefts, (42) has the assertive meaning component (42a) and the presupposition (42b).

(42) It was only John that came.

a. $\quad[\lambda \mathcal{Q} . \mathcal{Q}(\lambda x$.came $(x))](\llbracket$ only John $\rrbracket) \quad(\equiv \llbracket$ only John $\rrbracket(\lambda x$.came $(x)))$

b. $\forall \mathcal{P} \in \max (\lambda \mathcal{Q} . \mathcal{Q}(\lambda x$.came $(x))): \llbracket$ only John $\llbracket \not \subset \mathcal{P} \rrbracket$

Since only John is not part of any other quantifier, the presupposition (42b) is a tautology, which makes it effectively vanish. But of course (42), as a whole,

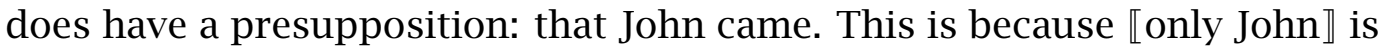
a partial function such that (42a) is only defined if John came. As a result, clefts with only DP as their pivot end up equivalent to ordinary predication (with only).

We are furthermore in a position to explain the difference between (43a) and (43b):

(43) a. It was John or Mary that came.

b. It was John or Mary or both that came.

(43a) suffers a presupposition failure if both John and Mary came, while (43b) is true in such a context. The reason is that John or Mary is not exhaustively true of a predicate which holds of both, while John or Mary or both is.

21 Proof:

$D P$ to only DP: Assume that $\mathcal{Q}$ is part of $\llbracket \mathrm{DP} \rrbracket$. Since $\operatorname{exh}(\llbracket \mathrm{DP} \rrbracket, P)$ entails $\llbracket$ only $\mathrm{DP} \rrbracket(P)$, Condition 1 for $\mathcal{Q} \sqsubset \llbracket$ only DP $\rrbracket$ is fulfilled. Since $\llbracket$ only $\mathrm{DP} \rrbracket(P)$ entails $\llbracket \mathrm{DP} \rrbracket(P)$, Condition 2 is also fulfilled.

only $D P$ to $D P$ : Assume that $\mathcal{Q}$ is part of $\llbracket$ only $\mathrm{DP} \rrbracket$. Condition $\mathrm{i}$ for $\mathcal{Q} \sqsubset \llbracket D P \rrbracket$ is fulfilled because $\llbracket$ only $D P \rrbracket(P)$ entails $\operatorname{exh}(\llbracket \mathrm{DP} \rrbracket, P)$. Furthermore, $\llbracket \mathrm{DP} \rrbracket$ holds only of predicates that are supersets of those that $\llbracket$ only DP $\rrbracket$ holds of (by the definition of exhaustivity). Since

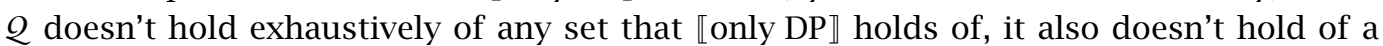
superset of such a set. Hence, $\mathcal{Q}$ is not true of any predicate that $\llbracket \mathrm{DP} \rrbracket$ is true of. 
Daniel Büring and Manuel Križ

\subsection{Intensional clefts}

It is also possible to cleft the quantificational complements of opaque verbs:

(44) It's a hat that I want.

Assuming a standard Hintikka-style analysis, where want takes a quantifier intension as its complement, we have the right types here to apply our cleft schema. All we need is a notion of parthood among quantifier intensions. This is easily supplied:

(45) A quantifier intension $\mathcal{P}$ is a proper part of a quantifier intension $\mathcal{Q}$ (written $\mathcal{P} \sqsubset \mathcal{Q}$ ) iff

1. $\exists w, P: \mathcal{P}_{w}\left(P_{w}\right) \wedge \operatorname{exh}\left(Q_{w}, P_{w}\right)$, and

2. $\forall w, P: \mathcal{Q}_{w}\left(P_{w}\right) \rightarrow \neg \operatorname{exh}\left(\mathcal{P}_{w}, P_{w}\right)$.

For all practical purposes, this results in the same parthood relations as we saw in the last section for quantifier extensions. ${ }^{22}$ Consequently, (44) suffers a presupposition failure in a situation where I want both a hat and a coat. Crucially, $\llbracket$ a hat $\rrbracket$ is not a part of $\llbracket$ a green hat $\rrbracket$ : any (concept of a) singleton of a green hat is a counterexample to parthood Condition 2. So a cleft like (44) does not presuppose that I want nothing more specific than just any hat. It may well be uttered in a situation where I actually desire a green hat in particular. This would be difficult to account for without recourse to the notion of parthood between quantifiers. ${ }^{23}$

\section{Speculative remarks: exhaustivity and existence}

So far we haven't talked about the existence presupposition, except that we assumed it to be there in addition to the exhaustivity claim, which was formulated so as to not entail it. In this section we want to point out a few phenomena and contrasts that follow from exhaustivity, assuming there is no existence presupposition.

For example, consider the following dialog (where the first sentence is to be intoned as an alternative question): ${ }^{24}$

22 In principle, we could subsume the extensional case under this if we abstracted over quantifier intensions in the relative clause.

23 E. g. with the conditional exhaustivity presupposition that was suggested in Büring 2011. 24 Boldface indicates stress. 
Exhaustivity and homogeneity presuppositions in clefts

(46) Did John call Mary, or Mary John?

a. It was John who called Mary.

b. John is the one who called Mary.

We think neither (46a) nor (46b) can be assumed to presuppose that someone called Mary in the context of (46). While it does follow from (46) - as an alternative question, anyway - that a call between John and Mary was made, whether someone called Mary (i. e. whether Mary, as opposed to John, was called) is precisely the point being asked. ${ }^{25}$

So there doesn't seem to be an existence presupposition here. But that isn't all: (46) contrasts with (47):

(47) Who called whom?

a. John called Mary, and Sue called Bill.

b. \#It was John who called Mary, and it was Sue who called Bill.

Unlike (47a), (47b) is only fine if it was presupposed that Mary and Bill received calls (or at any rate were supposed to be called). While this would follow from an existence presupposition for the ... who called John/Bill clause in the clefts, this can't be the story in light of (46) above. But then what is the difference between (46) and (47)?

Exhaustivity may provide a clue here. The exhaustivity presupposition associated with (46a) and the first clause in (47b) is given in (48):

(48) John is not a part of a larger sum of Mary-callers

It seems clear why (48) would be met in the context of (46): Since only one call is under discussion, at most one person (or called group) called Mary. (48), on the other hand, wouldn't be met in a run-of-the-mill scenario of the sort: for each of a given group of people, tell me who they called (i. e. what appears to be the neutral meaning conveyed by a question like (47)). If on the other hand it was known that Mary and Bill were supposed to be called, the presupposition would again be met.

A second class of examples relates to talk about hypothetical or potential individuals, this time involving definites. As pointed out by David Schueler (p.c. and Schueler 2008), existential nominals in subjunctive hypotheticals usually have to be indefinite, as in (49):

25 Such vice versa clefts are discussed in Ball \& Prince 1978, Hedberg in press: §3.1, Carlson 1983: 234; see particularly Hedberg's paper for more examples and discussion. 
(49) I hope the others won't be there. I would regret an/\#the altercation.

If a definite article is used, the sentence as a whole seems to presuppose something about the altercation in question (e.g. it has been described and discussed before); pretheoretically, the indefinite makes sense because the sentence introduces the altercation as a hypothetical: if there were an (not: the) altercation, I would regret that.

In certain cases, notably with event nominals, though, a definite is used:

(50) Be careful where you dig! I would regret the destruction of the old bench.

Crucially, this sentence does not seem to presuppose anything about the destruction of the old bench; like (49), it introduces a hypothetical: if the bench were destroyed, I would regret that. Based on these intuitions (which closely follow the analysis in Schueler 2008), it seems that the definite in (50) asserts, rather than presupposes, existence the same way the indefinite in (49) does.

What does set (49) and (50) apart is of course that the destruction of the old bench is by necessity a unique event, while the altercation isn't. In other words, the destruction of the bench licenses a presupposition to the effect that if there is a destruction of the bench, that would be the exhaustive/unique destruction of the bench. This seems remarkably similar to the presupposition we proposed for definites and clefts above.

What can we conclude from the data in this section? Arguably, good is done by an exhaustivity presupposition along the lines explored here. However, the effects discussed in this section (unlike those connected to identity statements and simple clefts discussed initially) are only explained by the exhaustivity presupposition if we assume at the same time that there is no existence presupposition (which would seem to be violated in all the cases discussed).

On the other hand, there is strong evidence that clefts and definites do have existential presuppositions (for clefts see e.g. the arguments in Dryer 1996, Rooth 1999), so we can't very well dismiss them generally. Perhaps a more cautious approach is to say that existence presupposition and exhaustivity presupposition in definites (and clefts) are independent of each other. Under certain, as of yet ill-understood, circumstances, the existence presupposition can somehow be ignored, while the exhaustivity presupposition is still active. These would be the cases discussed in this 
Exhaustivity and homogeneity presuppositions in clefts

section. $^{26}$

\section{Summary and Conclusion}

In this note, we have proposed a new exhaustivity presupposition for clefts. That presupposition amounts to the statement that any individual in the domain of the function denoted by it was... that $P$ is not a proper part of the maximal individual in the extension of $P$, which entails that if the individual is in $P$, then it is the maximal $P$. This was shown to explain the peculiar status of exhaustivity in clefts: it is not asserted, yet seemingly disappears under negation and similar presupposition filters. Our formal account also makes correct non-trivial predictions for collective predicates.

Furthermore, the account seems promising with respect to extension to clefting of elements that are of higher type and do not denote individuals. With a proper notion of parthood for such elements, it turns out that it straightforwardly captures the clefting of the quantifier objects of intensional verbs as in It was a hat that I wanted. Analyzing only DP as a quantifier, the use of higher types also allows for an explanation of the very peculiar behavior of clefts with only, in which the usual presupposition of clefts seems to be wholly absent.

We also showed that identity statements with definite descriptions show the same presuppositional behavior as clefts and can be treated in parallel, which is in line with the claims in e.g. Percus 1997. However, our account does not in principle depend on this connection.

Finally, we added some data in which the exhaustivity presupposition contemplated here, which does not, in its strict formulation, entail any kind of existence presupposition, would seem to explain a number of surprising contrasts. Their analysis, however, ultimately hinges on a proper treatment of the existential presupposition in definites and clefts, which we did not discuss at any length.

26 Cancellation of the existence presupposition in a cleft has also been argued for a. o. by Delahunty (1981), Gazdar (1979), Halvorsen (1978), Hedberg (in press), Keenan (1971), Levinson (1983) using examples like (i) (this one from Hedberg's paper):

(i) You believe that Mary kissed someone in this room. But it wasn't Joe that she kissed, and it wasn't Rita, and clearly it wasn't Bill, and there hasn't been anyone else here. Therefore, Mary didn't kiss anybody in this room.

Whether this is the same effect as in the examples in the main text, however, and when it occurs, is not clear to us. 


\section{Appendix: Atlas \& Levinson 1981}

(We discuss this proposal here since it is the only detailed one we know of that neither makes exhaustivity an entailment, nor a singularity presupposition/implicature, so comparison may be instructive.) According to Atlas \& Levinson (1981), (51) has the logical form in (51a) (adapted to our typographic conventions):

(51) It was John that Mary kissed.

a. $\quad[\lambda x \cdot x=\mathrm{John}](\gamma x \operatorname{kiss}($ Mary, $x))$

$\gamma$ is defined as in (52) ...

(52) 'We contextually define $\mathbf{B}(\gamma \mathbf{x A}(\mathbf{x}))$ as $\exists \mathbf{x A}(\mathbf{x}) \& \forall \mathbf{x}(\mathbf{A}(\mathbf{x}) \rightarrow \mathbf{B}(\mathbf{x}))$ ' (fn. 17, p. 53)

$\ldots$ yielding (53) as the truth conditions for (51):

(53) Someone kissed Mary, and everyone who kissed Mary is identical to John.

For its negation (54a), we get (54b), which 'by the Principle of Informativeness, yields as a generalized conversational implicatum of [(54a)] the internal negation [(54c)]' (p.55, example (143)):

(54) a. It wasn't John that Mary kissed.

b. $\neg[\lambda x \cdot x=\mathrm{John}](\gamma x$ kiss $($ Mary, $x))$

c. $[\lambda x . x \neq \operatorname{John}](\gamma x \operatorname{Kiss}($ Mary, $x))$

By the contextual definition quoted in (52), (54c) yields (55)...

(55) $\exists x[$ kiss (Mary, $x)] \& \forall x($ kiss (Mary, $x) \rightarrow x \neq$ John)

So if in fact John and Gord kissed Mary, (54a)/(55) is false (since not every Mary-kisser is distinct from John), as is its non-negated counterpart (51) (since not every Mary kisser is John). This agrees with the present account on truth conditions, but predicts the negated subset cases, which we have be undefined and all other analysis have as true, to be false.

But even granting the effect of the Principle of Informativeness (which, it should be noted, does look a bit like presuppositionalizing all but the B part in the meaning of $\gamma$ ), it is less clear that it correctly treats (56), which, recall, 
Exhaustivity and homogeneity presuppositions in clefts

should not be counted as true in Scenario 1:

(56) Gus didn't know that it was John that Mary kissed.

[Scenario 1:] Gus knew that John kissed Mary, but didn't know that no one else kissed Mary.

Clearly Gus does not know (53) in Scenario 1, so prima facie, (56) is predicted to be true. But as discussed, (56) is intuitively true only if Gus didn't know that John kissed Mary; and that statement is wrapped into the universal statement in Atlas \& Levinson's logical form, so it is at best unclear how this should come about on their account.

In addition, and more clearly, the account in Atlas \& Levinson 1981 fails in plural cases like (57):

(57) It was John, Bob and Gord that Mary kissed.

According to Atlas \& Levinson (1981: 54) the argument of kiss here is a sequence of individuals, which we write here as [John,Bob,Gord], and $x$ in (57)'s logical form (58) ranges over such sequences

$$
\begin{aligned}
& {[\lambda x \cdot x=[\text { John, Bob,Gord }](\gamma x \operatorname{kiss}(\text { Mary }, x))} \\
& \equiv \exists x[\operatorname{kiss}(\text { Mary }, x)] \& \forall x(\operatorname{kiss}(\text { Mary }, x) \rightarrow x=[\text { John, Bob,Gord }])
\end{aligned}
$$

Atlas \& Levinson (1981) don't give a precise characterization of what sequences (which they also call 'vectors' and 'lists') are, but note that (58) could only be true if none of [John,Bob], [John,Gord], [Bob,Gord], [John], [Bob], or [Gord] make $\lambda x$.kiss (Mary, $x$ ) true. But if kiss corresponds to natural language kiss, clearly the entailments from kiss(Mary, [John,Bob,Gord]) to kiss (Mary, [John,Bob]) etc. should hold, regardless of what exactly a sequence is. The only way the entailment would not hold is if kiss were itself already 'exhaustified', i. e. held of the maximum sequence of kissers only. But this would not only beg the question, it would make (55) true even if John and Gord kissed Mary (since the only value for $x$ then would be [John,Gord] (not John, or [John] etc.), and obviously [John,Gord] $\neq$ John), setting us back to square one. 
Daniel Büring and Manuel Križ

\section{References}

Akmajian, Adrian. 1970. On deriving cleft sentences from pseudo-cleft sentences. Linguistic Inquiry 1(2). 149-168. http://www.jstor.org/stable/ 4177550 .

Atlas, Jay \& Stephen C. Levinson. 1981. It-clefts, informativeness, and logical form. In Peter Cole (ed.), Radical pragmatics, 1-61. New York, NY: Academic Press.

Bach, Kent. 1999. The myth of conventional implicature. Linguistics and Philosophy 22(4). 327-366. http://dx.doi.org/10.1023/A:1005466020243.

Ball, Catherine N.\&Ellen Prince. 1978. A note on stress and presupposition. Linguistic Inquiry 8(3). 585. http://www.jstor.org/stable/4178000.

Büring, Daniel. 2011. Conditional exhaustivity presuppositions in clefts (and definites). Ms. ZAS/University of Vienna.

Carlson, Lauri. 1983. Dialog games: An approach to discourse analysis. Dordrecht: Reidel.

Champollion, Lucas. 2010. Parts of a whole: Distributivity as a bridge between aspect and measurement. Philadelphia, PA: University of Pennsylvania $\mathrm{PhD}$ thesis.

Delahunty, Gerald. 1981. Topics in the syntax and semantics of English cleft sentences. Irvine, CA: University of California PhD thesis.

Dryer, Matthew. 1996. Focus, pragmatic presupposition and activated propositions. Journal of Pragmatics 26(4). 473-523. http://dx.doi.org/10.1016/ o378-2166(95)ooo59-3.

von Fintel, Kai. 1997. Bare plurals, bare conditionals, and only. Journal of Semantics 14(1). 1-56. http://dx.doi.org/10.1093/jos/14.1.1.

Fodor, Janet Dean. 1970. The linguistic description of opaque contexts. Cambridge, MA: Massachusetts Institute of Technology PhD thesis. http://dx. doi.org/1721.1/12970.

Gajewski, Jon. 2005. Neg-raising: Presupposition and polarity. Cambridge, MA: Massachusetts Institute of Technology PhD thesis. http://dx.doi.org/1721. 1/33696.

Gazdar, Gerald. 1979. Pragmatics: Implicature, presupposition and logical form. New York, NY: Academic Press.

Groenendijk, Jeroen \& Martin Stokhof. 1984. Studies in the semantics of questions and the pragmatics of answers. University of Amsterdam PhD thesis. http://dare.uva.nl/en/record/123669. 
Exhaustivity and homogeneity presuppositions in clefts

Halvorsen, Per-Kristian. 1978. The syntax and semantics of cleft constructions. Austin, TX: University of Texas PhD thesis.

Han, Chung-Hye \& Nancy Hedberg. 2008. The syntax and semantics of it-clefts: A Tree-Adjoining Grammar analysis. Journal of Semantics 25(4). 345-380. http://dx.doi.org/10.1093/jos/ffnoo7.

Harries-Delisle, Helga. 1978. Contrastive emphasis and cleft sentences. In Joseph H. Greenberg (ed.), Universals of human language: Syntax, 419486. Stanford, CA: Stanford University Press.

Hedberg, Nancy. 2000. The referential status of clefts. Language 76. 891-920. http://dx.doi.org/10.2307/417203.

Hedberg, Nancy. in press. Multiple focus and cleft sentences. In Andreas Haida, Tonjes Veenstra \& Katharina Hartmann (eds.), The structure of clefts (Linguistik Aktuell). John Benjamins.

Heim, Irene. 1983. On the projection problem for presuppositions. West Coast Conference on Formal Linguistics (WCCFL) 2. 114-125.

Heim, Irene \& Angelika Kratzer. 1998. Semantics in generative grammar. Oxford: Blackwell Publishers.

Hintikka, Jaako. 1969. Semantics for propositional attitudes. In John W. Davis, Donald J. Hockney \&Warren K. Wilson (eds.), Philosophical logic. Dordrecht: Reidel. http://dx.doi.org/10.1007/978-94-010-9614-O_2.

Horn, Laurence R. 1969. A presuppositional analysis of only and even. Chicago Linguistic Society (CLS) 5. 98-107.

Horn, Laurence R. 1981. Exhaustiveness and the semantics of clefts. North East Linguistic Society (NELS) 11. 125-142.

Horn, Laurence R. 1996. Exclusive company: Only and the dynamics of vertical inference. Journal of Semantics 13(1). 1-40. http://dx.doi.org/10.1093/jos/ 13.1.1.

Ippolito, Michela. 2008. On the meaning of only. Journal of Semantics 25(1). 45-91. http://dx.doi.org/10.1093/jos/ffmo10.

Keenan, Edward L. 1971. Two kinds of presupposition in natural language. In Charles J. Fillmore \& D. Terrence Langendoen (eds.), Studies in linguistic semantics, 45-54. Holt, Rinehart \& Winston.

Kiss, Katalin É. 1998. Identificational focus and information focus. Language 74(2). 245-273. http://dx.doi.org/10.2307/417867.

Levinson, Stephen C. 1983. Pragmatics. Oxford: Cambridge University Press. Link, Godehard. 1983. The logical analysis of plurals and mass terms: A lattice-theoretic approach. In Rainer Bäuerle, Christoph Schwarze \& Arnim 
von Stechow (eds.), Meaning, use and interpretation of language, 302-323. Berlin: De Gruyter.

Löbner, Sebastian. 1987. The conceptual nature of natural language quantification. In Imra Rusza \& Anna Szabolcsi (eds.), Proceedings of the 1987 Debrecen symposium on logic and language. Budapest: Akadémiai Kaidó. Löbner, Sebastian. 200o. Polarity in natural language: Predication, quantification and negation in particular and characterizing sentences. Linguistics and Philosophy 23(3). 213-308. http://dx.doi.org/10.1023/A: 1005571202592.

McCawley, James D. 1981. Everything that linguists have always wanted to know about logic but were ashamed to ask. Chicago, IL: University of Chicago Press.

Percus, Orin. 1997. Prying open the cleft. North East Linguistic Society (NELS) 27. 337-351.

Potts, Christopher. 2007. Conventional implicatures: A distinguished class of meanings. In Gillian Ramchand \& Charles Reiss (eds.), The Oxford handbook of linguistic interfaces (Studies in Theoretical Linguistics), 475-501. Oxford: Oxford University Press.

van Rooij, Robert \& Katrin Schulz. 2006. Pragmatic meaning and non-monotonic reasoning: The case of exhaustive interpretation. Linguistics and Philosophy 29(2). 205-250. http://dx.doi.org/10.1007/s10988-005-3760-4.

Rooth, Mats. 1985. Association with focus. Amherst, MA: University of Massachusetts $\mathrm{PhD}$ thesis.

Rooth, Mats. 1999. Association with focus or association with presupposition. In Peter Bosch \& Rob Van Der Sandt (eds.), Focus: Linguistic, cognitive, and computational perspectives, 232-244. Cambridge University Press.

Schueler, David. 2008. The syntax and semantics of implicit conditionals: Filling in the antecedent. Los Angeles, CA: University of California PhD thesis.

Schwarzschild, Roger. 1994. Plurals, presuppositions and sources of distributivity. Natural Language Semantics 2(3). 201-248. http://dx.doi.org/10. 1007/BFo1256743.

Sevi, Aldo. 2005. Exhaustivity: A semantic account of 'quantity' implicatures. Tel Aviv University $\mathrm{PhD}$ thesis.

Wedgewood, Daniel. 2007. Identifying inferences in focus. In Kerstin Schwabe \& Susanne Winkler (eds.), On information structure, meaning, and form, 207-227. Amsterdam \& Philadelphia, PA: John Benjamins. 
Exhaustivity and homogeneity presuppositions in clefts

Daniel Büring

Department of Linguistics

University of Vienna

Sensengasse $3 \mathrm{a}$

1090 Vienna

Austria

daniel.buring@univie.ac.at
Manuel Križ

Department of Linguistics

University of Vienna

Sensengasse $3 \mathrm{a}$

1090 Vienna

Austria

manuel.kriz@univie.ac.atl 